Published in final edited form as:

Obstet Gynecol Clin North Am. 2018 June ; 45(2): 233-247. doi:10.1016/j.ogc.2018.01.001.

\title{
Management of Obstructive Sleep Apnea in Pregnancy
}

\author{
Jennifer E. Dominguez, MD, MHS, \\ Assistant Professor, Department of Anesthesiology, Program Director, Obstetric Anesthesiology \\ Fellowship Program, Division of Women's Anesthesia, Duke University Medical Center, Durham, \\ NC USA
}

\author{
Linda Street, MD, and \\ Assistant Professor, Division of Maternal Fetal Medicine, Department of OB/GYN, Medical \\ College of Georgia at Augusta University, Augusta, Georgia USA
}

Judette Louis, MD, MPH

Associate Professor, Division of Maternal Fetal Medicine, Department of OB/GYN, MFM Division Chief and Fellowship Director, University of South Florida, Tampa, Florida USA

\section{SYNOPSIS}

The spectrum of sleep disordered breathing (SDB) ranges from mild snoring to obstructive sleep apnea (OSA), the most severe form of SDB. Current recommendations are to treat these women with continuous positive airway pressure (CPAP) despite limited data. SDB in early and midpregnancy were associated with preeclampsia and gestational diabetes. Pregnant women with a diagnosis of OSA at delivery were at significantly increased risk of having cardiomyopathy, congestive heart failure, pulmonary embolism and in-hospital death. These effects were exacerbated in the presence of obesity. Postpartum, these women are at risk for respiratory suppression and should be monitored.

\section{Keywords}

Obstructive sleep apnea; obesity; pregnancy; diabetes; preeclampsia; anesthesia; sleep disordered breathing; hypoxia

\begin{abstract}
Obstetric patients have been under-recognized as a population at risk for sleep-disordered breathing (SDB). SDB is likely underappreciated in pregnancy due to a number of factors including: limited provider education; a lack of reliable screening tools; and a need for additional studies characterizing the dynamic effects of pregnancy on SDB and perinatal
\end{abstract}

\footnotetext{
Corresponding Author: Judette Louis MD, MPH, 2 Tampa General Circle Suite 6050, Tampa, FL 33606, Jlouis1@ health.usf.edu. AUTHOR CONTACT INFORMATION

Jennifer Dominguez: Duke University Medical Center, Mail Sort \#9, DUMC Box 3094, Durham, NC 27710, jennifer.dominguez@dm.duke.edu

Linda Street: $112015^{\text {th }}$ Street, BA-7410, Augusta, GA 30912, Phone: (706) 721-3556, listreet@augusta.edu

DISCLOSURE STATEMENT

Disclosure of any relationship with a commercial company that has a direct financial interest in subject matter or materials discussed in article or with a company making a competing product

Linda Street: No Disclosures

Judette Louis: No Disclosures
} 
outcomes. ${ }^{1}$ In addition, several of the most common risk factors for SDB recognized by clinicians were established from studies that excluded women of reproductive age. ${ }^{2}$ It is now recognized that SDB may present differently in women of reproductive age, which can further complicate screening and diagnosis. ${ }^{3}$

Studies of SDB in recent years indicate there are significant implications for pregnancy. Women affected by SDB are more likely to experience pregnancy complications and adverse pregnancy outcomes. ${ }^{4-10}$ In this article we will review SDB, the implications for pregnancy and ways that a practicing physician can improve clinical outcomes.

\section{What is SDB?}

SDB is a group of disorders characterized by ventilation abnormalities during sleep. The spectrum of SDB ranges from mild snoring to obstructive sleep apnea (OSA), the most severe form of SDB. ${ }^{11}$ OSA involves multiple episodes of apnea or hypopnea during sleep that result from diminished airflow through the upper airway during respiratory effort, due to partial or complete upper airway tissue collapse. This phenomenon leads to sleep fragmentation, sympathetic stimulation, hypercarbia, and intermittent cycles of hypoxemia and reoxygenation. ${ }^{12}$ These pathophysiologic perturbations in turn contribute to inflammation, endothelial dysfunction, insulin resistance, and cardiovascular disease. ${ }^{12}$ Repeated nocturnal arousals can result in excessive daytime sleepiness, and can be at increased risk when driving or operating machinery. ${ }^{12-14}$ The terms SDB and sleep apnea have been used interchangeably in the obstetric literature.

\section{Gestational OSA}

Women diagnosed with OSA during pregnancy likely represent one of two distinct clinical phenotypes: women with pre-existing OSA that become pregnant (chronic OSA); and pregnant women who develop OSA (gestational OSA). Women with gestational OSA may enter pregnancy with snoring, and develop worsening airway obstruction due to physiologic and hormonal changes of pregnancy or in association with other comorbidities developed in pregnancy (multiple gestations, hypertensive disorders of pregnancy, or gestational diabetes). Some physiologic changes of pregnancy that may predispose women to OSA include upper airway edema and respiratory-driven changes leading to larger negative upper airway pressures due to elevated estrogen and progesterone. ${ }^{15}$ There is some evidence that gestational OSA may improve or resolve entirely after pregnancy. ${ }^{16-18}$ However, the term "gestational sleep apnea" has not been formally defined. To date, the progression and impact of these two phenotypes has not been well described in either the perinatal period or beyond.

\section{Epidemiology and Risk Factors}

The risk factors for OSA are well established in the general population and include: male gender, older age, obesity, African-American race, craniofacial abnormalities, and smoking. 19,20 OSA is also associated with other co-morbid conditions including: type II diabetes, hypertension, cardiac arrhythmias and cardiovascular disease. ${ }^{12}$ Women who have those risk factors prior to pregnancy may be at increased risk for OSA. The existing studies in 
pregnancy also recognize increasing gestation, increasing maternal age, obesity, chronic hypertension, and frequent snoring ( $\geq 3 \mathrm{x} /$ week) as risk factors. ${ }^{8,10,21}$ In the largest prospective study to date, women with OSA were older, had higher body mass index, larger neck circumference, and were more likely to have chronic hypertension, which is consistent with prior studies. ${ }^{6}$

Longitudinal studies of OSA indicate an increased prevalence across gestation. ${ }^{6,22}$ In the largest prospective study currently published, the prevalence of OSA was estimated to be $3.6 \%$ in early pregnancy and increased across gestation with rates as high as $26 \%$ in the third trimester among the 3,132 nulliparous women who completed objective testing for OSA. ${ }^{6}$ These data are congruent with the findings of Pien et al. which also found an increase from $10.5 \%$ women with OSA in the first trimester to $26.7 \%$ in the third trimester among a group of women who underwent overnight polysomnography at the two time points in pregnancy. ${ }^{22}$ While the first trimester prevalence likely represents women with preexisting chronic OSA, the increase throughout gestation is evidence of impact of pregnancy on the prevalence of the disease. With increased obesity rates, OSA is expected to affect a greater proportion. Approximately $15 \%-20 \%$ of obese pregnant women are estimated to have $\mathrm{OSA}^{7,10,21}$. With delayed childbearing, women are older at the time of their first pregnancy, further increasing the risk for OSA.

\section{Screening and Diagnosis}

The screening questionnaires developed and validated in the non-pregnant population (Berlin questionnaire, Epworth Sleepiness Scale, and STOP-BANG questionnaires) have not been demonstrated to be useful in the obstetric population with reported sensitivities and specificities that are $36-39 \%$ and $68-77 \%$ respectively in current literature. ${ }^{7,} 23-27$ While they are limited, in the absence of a better screening tool, some clinicians choose to use them. As an alternative, Facco et al. proposed that most cases of OSA can be identified using 3 factors: age, BMI and presence of chronic hypertension. ${ }^{21}$ Larger scale studies are needed to identify the best approach for screening pregnant women.

The gold standard for the diagnosis of OSA is overnight, attended, in-lab polysomnography (in-lab PSG). ${ }^{14}$ However, in many medical centers, the availability of in-lab polysomnography requires significant wait times that may not allow for treatment to occur during pregnancy. Further, in-lab PSG is costly, and requires an overnight, inpatient stay, which may not be practical for many patients that are unable to spend a night away from children in the home. Due to these challenges, many sleep physicians and insurers are turning to home sleep testing using portable devices as a practical alternative for select populations. Home sleep apnea testing devices have been used in several studies with pregnant women and some have been validated in pregnant populations. ${ }^{10,21,28}$ However, although home sleep testing is widely accepted, there are some limitations. Home sleep tests are unattended and do not measure sleep time with EEG, so they are prone to underestimate sleep apnea severity or provide false negative results. ${ }^{14,29}$ They are particularly confounded by frequent waking during sleep such as occurs for many pregnant women who may have a more frequent need to urinate. Routine EEG offers direct clinical observation along with electrophysiologic and cardiorespiratory monitoring to measure actual sleep time; most 
home tests are missing that component. ${ }^{30}$ Despite these limitations, home sleep testing is likely to detect moderate to severe OSA, especially when utilizing mild range apneahypopnea index (AHI) scores ( $>5 /$ hour) as the threshold for treatment or further testing. ${ }^{31}$ Sleep apnea severity is scored based on the AHI, a measure of how many apneas (cessation of airflow for $\geq 10$ seconds accompanied by an arousal or oxyhemoglobin desaturation) and hypopneas (reduction of airflow for $\geq 10$ seconds accompanied by an arousal or oxyhemoglobin desaturation) are present per hour of sleep. Mild OSA is defined as $5 \leq \mathrm{AHI}$ $<15 /$ hour, moderate is considered $15 \leq \mathrm{AHI}<30$, and severe OSA is 30 or greater/hour. ${ }^{32}$

Some insurers prefer that their insured customers receive home sleep tests instead of in-lab PSG due to the cost savings as proof of diagnosis of OSA for coverage of continuous positive airway pressure (CPAP) therapy; the Centers for Medicare and Medicaid Services began covering home sleep testing in $2016 .{ }^{33}$ At this point, due to barriers of in-lab studies, home sleep testing is a viable alternative in select patients. However, the results should be interpreted with caution, and if significant clinical suspicion for OSA remains, it is recommended that the patient undergo overnight, in-lab PSG. ${ }^{14}$

\section{Treatment}

In the general population, CPAP is the preferred treatment for mild, moderate, and severe OSA. ${ }^{34}$ More than 15 randomized clinical trials in the general population have suggested that treatment reduces hypertension, cardiovascular morbidities, and motor vehicle crashes. 35-38 While the data on improvement of symptoms, quality of life and automobile crashes have been consistent, recent data have failed to demonstrate a benefit in the reduction of cardiovascular disease. ${ }^{39}$ However, some of the difficulty in finding a difference may be due to diminished efficacy of CPAP secondary to poor patient adherence. Customized oral mandibular repositioning devices are an alternative that keep the airway open by pulling the lower jaw forward. While these oral devices can be an effective treatment for mild to moderate OSA for individuals with good dentition, they are considered second line treatment and only recommended if the patient cannot tolerate CPAP or desire alternative therapy. ${ }^{40}$

There are few data to direct the treatment of OSA in pregnancy. Small studies examined CPAP treatment using short-term intermediary outcomes such as maternal blood pressure. 41-43 However, with such small sample sizes, they were insufficiently powered to detect treatment impact or safety. Therefore, despite a consistent body of evidence showing an increased risk of adverse pregnancy outcomes associated with OSA in pregnancy, we do not have evidence that treatment in the short term of pregnancy improves maternal or neonatal outcome. Rather, the benefits demonstrated in the general populations and the existing treatment guidelines are extrapolated to pregnancy. ${ }^{34}$

\section{Maternal morbidity}

The Sleep Disordered Breathing Sub-study of the Nulliparous Pregnancy Outcomes Study was a multicenter, prospective cohort study seeking to investigate whether sleep-disordered breathing during pregnancy is a risk factor for the development of hypertensive disorders of 
pregnancy and gestational diabetes. ${ }^{6,18}$ The vast majority of these subjects who tested positive for OSA in their pregnancies had mild-moderate OSA (AHI 5-14.9/hour). SDB in early and mid-pregnancy were associated with preeclampsia [adjusted Odds Ratio (aOR) 1.94 (95\% CI 1.07-3.51) and 1.95 (95\% CI 1.18-3.23)], and gestational diabetes (GDM) [aOR 3.47 (95\% CI 1.95-6.19) and 2.79 (95\% CI 1.63-4.77)]. There was a demonstrated dose response for women with severe OSA in mid-pregnancy (AHI > 15/h) showing an even greater risk of hypertensive diseases of pregnancy [aOR $=4.27$ (95\% CI, $1.74-10.45$ ]. The findings of that study confirmed the findings of other smaller retrospective and prospective cohort studies that consistently found a 2-fold increased adjusted odds of preeclampsia and a nearly 2 -fold increased adjusted odds of gestational diabetes in association with SDB or OSA, in two meta-analyses of the existing studies. ${ }^{8,44}$

Another study that included a military-treatment facility cohort indicated that the association persisted even in a "healthier cohort." Women with an OSA diagnosis were more likely to have a cesarean delivery (aOR, 1.60; 95\% CI, 1.06-2.40), gestational hypertension, (aOR, 2.46; 95\% CI, 1.30-4.68), preeclampsia (aOR, 2.42; 95\% CI, 1.43-4.09), and preterm delivery (aOR, 1.90; 95\% CI, 1.09-3.30). ${ }^{45}$

\section{Severe maternal morbidity}

Severe maternal morbidities are those clinical events that can proximally lead to maternal death. Evidence from a large, national inpatient database study showed that pregnant women with a diagnosis of OSA during their hospital admission (by diagnosis code) at delivery were at significantly increased risk of having cardiomyopathy [aOR $=9.0$ (95\% CI, 7.4710.87)], congestive heart failure [aOR $=8.94$ (95\% CI, 7.45-10.73)], and pulmonary embolism [aOR $=4.5$ (95\% CI, 2.3-8.9)]. This study also showed a 5-fold increase of inhospital mortality during a pregnancy or delivery in women with OSA. ${ }^{7}$ These effects were exacerbated in the presence of obesity. The findings appear to indicate an effect of OSA that is independent of obesity. This study has yet to be replicated with other data sets with large enough numbers to confirm these uncommon findings but suggest serious complications for pregnant women with OSA.

\section{Neonatal morbidity}

The adverse fetal and neonatal consequences of sleep apnea in pregnancy are delineated to a lesser extent than that of maternal consequences. Maternal OSA is associated with 1.5 to 2fold increased frequency of low birth weight and small for gestational age infants. ${ }^{8}, 46,47$ These findings persist after controlling for comorbid maternal conditions that predispose to growth restriction such as hypertension. ${ }^{8,46,47}$ However, associations with large for gestational age infants born to women with SDB have also been reported. ${ }^{48}$ This association may be partially explained by the high rates of maternal obesity and diabetes, two risk factors for large for gestational age infants.

Infants born to women with OSA are more likely to be born preterm and admitted to the NICU despite similar gestational age at delivery. ${ }^{10}$ Definitive studies examining the relationship do not exist. However, the findings are not completely unexpected given the 
high rates of cesarean delivery among women with OSA (up to 50\%). ${ }^{10}$ There are no studies that indicate an increased risk of fetal death or miscarriage in association with sleep apnea. ${ }^{7}$

In addition to the studies on immediate infant outcomes, smaller studies indicate that there may be longer term consequences for these infants. ${ }^{49,50}$ Seventy-four mom-baby pairs of which $24 \%$ had OSA were followed in one study. While there was no difference in general motor scores, there was an increased frequency of low social development scores in neonates of moms with OSA (64\% vs. $25 \%, \mathrm{p}=.036)$ at 12 months of age. ${ }^{49}$ Another recent study showed that the infants of women at risk for SDB determined by sleep questionnaires administered at hospital admission for delivery had shorter telomere lengths in the DNA collected from their cord blood. ${ }^{50}$ Shorter telomere length has been observed in the DNA of adults with OSA, and is associated with age-related disease. ${ }^{50,51} \mathrm{It}$ is difficult to draw conclusions from these small, preliminary studies, but they may inform future directions for research.

\section{Mechanisms of Disease}

To date, the mechanisms that link OSA to adverse outcomes of pregnancy have not been well defined. Sleep apnea is a state in which there is overlap of pro-inflammatory states, oxidative stress, and sympathetic activation. ${ }^{52}$ This cascade of events are thought to lead to endothelial dysfunction, although the role of oxidative stress in these pathways has been questioned by the findings of recent studies in non-pregnant and pregnant cohorts. ${ }^{15,53,54}$ Endothelial dysfunction has been implicated in non-pregnant adults to link OSA and cardiovascular disease. ${ }^{55}$ Some of these same mechanisms have been implicated in the development of preeclampsia and adverse pregnancy outcome. ${ }^{56}$ (Figure 1)

The pathophysiologic mechanisms that connect OSA with the associated cardiovascular and metabolic disease shares significant overlap with known pathways involved in preeclampsia. 57, 58 OSA and preeclampsia both seem to be pro-inflammatory states, and studies in both populations demonstrate sympathetic nervous system activation. ${ }^{59-62}$ To our knowledge, no studies have been done investigating these pathways in women with OSA and preeclampsia. In OSA, as in preeclampsia, up-regulation of antiangiogenic proteins seems to lead to endothelial dysfunction. ${ }^{63,64}$ This endothelial dysfunction is implicated in vasoconstriction, hypertension, and proteinuria associated with preeclampsia, and the hypertension and cardiovascular disease associated with OSA. ${ }^{65,66}$ Preliminary evidence that imbalances of pro-/anti-angiogenic proteins are associated with a diagnosis of OSA were found in a small retrospective study of pregnant women with OSA. 57

The explanations for the fetal growth abnormalities may differ. Pregnant women that live at high altitude have chronically low arterial oxygen partial pressures and studies have shown that they have an increased risk of hypertensive disorders of pregnancy and fetal growth restriction. ${ }^{67,68}$ Both animal model and human studies suggest that the placenta and fetus adapt via compensatory mechanisms to the low oxygen tension. 69,70

However, there are currently no studies in pregnant women with OSA that have specifically investigated the effects of repetitive, nocturnal exposure to hypoxemia in this disease state. 
69,70 In vitro and animal studies suggest that oxygen tension plays a very specific role in the early development of the placenta, and that alterations may predispose to the pathologic placental development that is subsequently seen in hypertensive disorders of pregnancy and fetal growth restriction (FGR). ${ }^{71-74}$ Hypoxia-inducible factors- $1 \& 2$ (HIF-1 \& 2) are transcription factors that play a vital role in the cellular response to low oxygen tension. ${ }^{75}$ HIF-1 \& 2 are overexpressed in the placentas of women living at high altitude, women with hypertensive disorders of pregnancy, and rats with growth restricted fetuses. ${ }^{76-78}$ HIFs have also been studied for their role in OSA with hypertension in non-pregnant adults, as mediators of hypoxemia, sympathetic nervous system activators, oxidative stress and endothelial dysfunction. ${ }^{79}$ These different mechanisms can serve as targets for future interventional studies.

\section{Long-term Implications of Sleep Apnea}

Untreated OSA has a bidirectional association with type II diabetes, cardiovascular disease and hypertension. ${ }^{80-82} \mathrm{We}$ also know that pregnancy is a time that most patients seek medical help, often for the first time, that gives us an opportunity to impact future health outcomes. Developing complications such as preeclampsia and gestational diabetes increases the future risk of cardiovascular disease and type II diabetes among the affected women. ${ }^{83-86}$ Due to this relationship, it is hypothesized that SDB and OSA may further predispose these women to future cardiovascular disease. The extent to which SDB impacts the already observed relationship between preeclampsia and cardiovascular disease is unknown. ${ }^{16,87}$ (Fig 2) It is also unknown if postpartum resolution of OSA has a lasting impact, or if treating OSA during pregnancy would modify these outcomes.

Future studies are needed to ascertain if treatment of OSA can impact the course of these comorbid diseases in pregnant women as their consequences are far reaching and extend beyond completion of pregnancy. Preeclampsia has been linked to a 3-12 fold increased risk of cardiovascular events later in life and a 2-8 fold increased risk of death from a cardiovascular event ${ }^{88,89}$. Up to $62 \%$ of women diagnosed with gestational diabetes go on to develop type II diabetes later in life ${ }^{90}$. This does not even begin to take into account the potential for gestational OSA to persist after pregnancy. Rates of long-term postpartum persistence of OSA or development of OSA later in life are not well defined at this time, but it is reasonable to presume that in some women gestational OSA is a precursor for life-long risks discussed above.

\section{Clinical Care}

\section{Antepartum care}

A multidisciplinary approach should be taken when managing pregnant women with OSA that should continue to the postpartum period. ${ }^{91}$ Women with known OSA who become pregnant should be evaluated by a sleep medicine specialist to optimize CPAP settings. The goal is to achieve and maintain a normalized AHI and oxygenation throughout gestation through the consistent use of CPAP therapy. Follow up visits or an automatically titrating CPAP machine are useful as CPAP requirements may increase with advancing gestation and worsening obstruction. $6,92,93$ The patient should be counseled about the known perinatal 
consequences of sleep apnea and a multidisciplinary plan must be formulated. Patients with moderate to severe OSA may have co-morbid cardiovascular disease or pulmonary hypertension, and echocardiography should be considered. Obstetric providers should be mindful of the risk of hypertensive disorders and diabetes and should focus on early detection or prevention of these conditions. Women who are suspected of having OSA but have not been diagnosed should be referred to a sleep medicine specialist for evaluation. Situations where a suspicion of sleep apnea may arise include but are not limited to, maternal symptoms of excessive daytime sleepiness or generalized fatigue, witnessed apneas, loud and frequent snoring, headaches and/or observed maternal hypoxia in the absence of cardiorespiratory pathology. ${ }^{92}$ After referral, the sleep medicine provider can evaluate the patient and make recommendations regarding diagnosis and management during the pregnancy and in the postpartum period. In the absence of pregnancy-specific data to direct treatment, we currently suggest treatment for all women with OSA. Studies have not been conducted to evaluate the safety of CPAP in pregnancy, but it widely accepted as safe in pregnancy. An individualized plan can be developed with the sleep medicine provider.

\section{Intrapartum and Immediate Postpartum Management}

Women with OSA are also more likely to have co-morbid conditions that also predispose them to cesarean deliveries. ${ }^{10}$ The American Society of Anesthesiologists guidelines advise preoperative evaluation and treatment of OSA is optimal in surgical patients. ${ }^{94}$ There are no guidelines specifically regarding pregnant women with OSA, however they represent a highrisk cohort and should be treated like other pre-surgical patients. ${ }^{9}$

Perioperative risks to gravid women with sleep apnea include a greater risk of difficult intubation and ventilation. When OSA is comorbid with severe obesity, neuraxial anesthesia which is the gold-standard anesthetic for cesarean delivery can be technically difficult. This can increase the need for conversion to general anesthesia. ${ }^{95} \mathrm{~A}$ pre-operative anesthesia consultation for airway assessment and evaluation for placement of neuraxial anesthesia should occur.

These women are at risk for postoperative respiratory suppression and should have continuous pulse oximetry monitoring after discharge from the recovery room; continuous oximetry should be maintained as long as patients remain at increased risk. ${ }^{96}$ While some institutions have implemented protocols which include monitoring for a 12 to 24 hour period of time, there are no studies to guide the effectiveness of these protocols and to determine the optimal duration of that monitoring. ${ }^{91}$ If frequent or severe airway obstruction or hypoxemia are noted, CPAP or noninvasive positive pressure ventilation in an ICU setting should be strongly considered. ${ }^{96}$ In a case series of anesthesia-related maternal deaths in Michigan, half of the anesthesia related deaths were determined to be due to lapses in postoperative monitoring, either in the post-anesthesia care unit (PACU) or the hospital room ${ }^{97}$. Patients should be encouraged to maintain a 45 -degree head elevation and avoid supine position as this was associated with a decrease in the number of apnea and hypopnea events in a study of post-partum women. ${ }^{98}$ Multi-modal post-operative analgesia with nonsteroidal anti-inflammatory agents and acetaminophen are recommended when possible to decrease the risk of sedation and hypoventilation associated with opioids. The use of 
neuraxial morphine in this population due to the theoretical risk of delayed respiratory depression is controversial. ${ }^{99}$ Some centers avoid the use of neuraxial morphine for postcesarean delivery analgesia in women with morbid obesity and OSA. Others have argued that the parenteral opioid sparing effect of a small dose of neuraxial morphine outweighs the small risk of respiratory depression. ${ }^{100}$ Transversus abdominis plane block, local anesthetic wound catheters and neuraxial techniques are options to consider for post-operative analgesia when appropriate. ${ }^{101}$ Sedating medications such as anti-emetics, anti-histamines, anxiolytics, and sleep aids should be avoided or used sparingly with extreme caution in monitored settings, particularly when used along with opioids. Standing order for narcotics and basal dosing should be avoided, while patient-controlled systemic opioids should be used very cautiously.

During the postpartum period, all women with a diagnosis or suspicion of OSA during pregnancy should be evaluated by a sleep medicine provider to allow for re-assessment of OSA severity and overall management/treatment strategy.

\section{Conclusion}

OSA in pregnancy is a common and under-recognized disorder that carries implications for both the mother and the fetus. These women are at a higher risk of pregnancy and anesthesia-related complications. A lack of effective screening tools and limited understanding of the dynamic effects of pregnancy on OSA throughout gestation continue to make diagnosis and management challenging. Increased awareness with appropriate diagnosis, treatment, and perioperative management could improve outcomes in these pregnancies although data on the impact of OSA treatment on adverse pregnancy outcomes are still needed. Additionally, identifying OSA early in a woman's life may positively impact her long-term health. As pregnancy is often the only time many young women seek health care, this may be the best opportunity for early detection in some at risk women.

\section{Acknowledgments}

Dr. Dominguez's work is supported in part by the NIH 5T32GM008600-20. Devices used in our research have been loaned by ResMed and Itamar Medical, Ltd

\section{References}

1. Bourjeily G, Raker C, Paglia MJ, Ankner G, O'Connor K. Patient and provider perceptions of sleep disordered breathing assessment during prenatal care: a survey-based observational study. Therapeutic Advances in Respiratory Disease. 2012; 6:211-219. [PubMed: 22556123]

2. Chung F, Subramanyam R, Liao P, Sasaki E, Shapiro C, Sun Y. High STOP-Bang score indicates a high probability of obstructive sleep apnoea. Br J Anaesth. 2012; 108:768-775. [PubMed: 22401881]

3. Shah N, Hanna DB, Teng Y, et al. Sex-Specific Prediction Models for Sleep Apnea From the Hispanic Community Health Study/Study of Latinos. CHEST. 149:1409-1418.

4. O'Brien LM, Bullough AS, Chames MC, et al. Hypertension, snoring, and obstructive sleep apnoea during pregnancy: a cohort study. BJOG. 2014; 121:1685-1693. [PubMed: 24888772]

5. O'Brien LM, Bullough AS, Owusu JT, et al. Pregnancy-onset habitual snoring, gestational hypertension, and preeclampsia: prospective cohort study. Am J Obstet Gynecol. 2012; 207:487 e481-489. [PubMed: 22999158] 
6. Facco FL, Parker CB, Reddy UM, et al. Association Between Sleep-Disordered Breathing and Hypertensive Disorders of Pregnancy and Gestational Diabetes Mellitus. Obstet Gynecol. 2017; 129:31-41. [PubMed: 27926645]

7. Louis JM, Mogos MF, Salemi JL, Redline S, Salihu HM. Obstructive sleep apnea and severe maternal-infant morbidity/mortality in the United States, 1998-2009. Sleep. 2014; 37:843-849. [PubMed: 24790262]

8. Pamidi S, Pinto LM, Marc I, Benedetti A, Schwartzman K, Kimoff RJ. Maternal sleep-disordered breathing and adverse pregnancy outcomes: a systematic review and metaanalysis. Am J Obstet Gynecol. 2014; 210:52 e51-52 e14. [PubMed: 23911687]

9. Xu T, Feng Y, Peng H, Guo D, Li T. Obstructive sleep apnea and the risk of perinatal outcomes: a meta-analysis of cohort studies. Sci Rep. 2014; 4:6982. [PubMed: 25382105]

10. Louis J, Auckley D, Miladinovic B, et al. Perinatal outcomes associated with obstructive sleep apnea in obese pregnant women. Obstet Gynecol. 2012; 120:1085-1092. [PubMed: 23090526]

11. Chervin RD, Guilleminault C. Obstructive sleep apnea and related disorders. Neurologic clinics. 1996; 14:583-609. [PubMed: 8871978]

12. Jordan AS, McSharry DG, Malhotra A. Adult obstructive sleep apnoea. Lancet. 2014; 383:736747. [PubMed: 23910433]

13. Alam I, Lewis K, Stephens JW, Baxter JN. Obesity, metabolic syndrome and sleep apnoea: all proinflammatory states. Obes Rev. 2007; 8:119-127. [PubMed: 17300278]

14. Kapur VK, Auckley DH, Chowdhuri S, et al. Clinical Practice Guideline for Diagnostic Testing for Adult Obstructive Sleep Apnea: An American Academy of Sleep Medicine Clinical Practice Guideline. J Clin Sleep Med. 2017; 13:479-504. [PubMed: 28162150]

15. Bourjeily G, Ankner G, Mohsenin V. Sleep-disordered breathing in pregnancy. Clin Chest Med. 2011; 32:175-189. x. [PubMed: 21277458]

16. Reid J, Glew RA, Skomro R, et al. Sleep disordered breathing and gestational hypertension: postpartum follow-up study. Sleep. 2013; 36:717-721B. [PubMed: 23633754]

17. Edwards N, Blyton DM, Hennessy A, Sullivan CE. Severity of sleep-disordered breathing improves following parturition. Sleep. 2005; 28:737-741. [PubMed: 16477961]

18. Facco FL, Parker CB, Reddy UM, et al. NuMoM2b Sleep-Disordered Breathing study: objectives and methods. Am J Obstet Gynecol. 2015; 212:542 e541-127. [PubMed: 25746730]

19. Young T, Peppard PE, Gottlieb DJ. Epidemiology of obstructive sleep apnea: a population health perspective. American journal of respiratory and critical care medicine. 2002; 165:1217-1239. [PubMed: 11991871]

20. Punjabi NM. The epidemiology of adult obstructive sleep apnea. Proc Am Thorac Soc. 2008; 5:136-143. [PubMed: 18250205]

21. Facco FL, Ouyang DW, Zee PC, Grobman WA. Development of a pregnancy-specific screening tool for sleep apnea. J Clin Sleep Med. 2012; 8:389-394. [PubMed: 22893769]

22. Pien GW, Pack AI, Jackson N, Maislin G, Macones GA, Schwab RJ. Risk factors for sleepdisordered breathing in pregnancy. Thorax. 2014; 69:371-377. [PubMed: 24262432]

23. Netzer NC, Stoohs RA, Netzer CM, Clark K, Strohl KP. Using the Berlin Questionnaire to identify patients at risk for the sleep apnea syndrome. Ann Intern Med. 1999; 131:485-491. [PubMed: 10507956]

24. Lockhart EM, Ben Abdallah A, Tuuli MG, Leighton BL. Obstructive Sleep Apnea in Pregnancy: Assessment of Current Screening Tools. Obstetrics \& Gynecology. 2015; 126:93-102. [PubMed: 26241261]

25. Chung F, Subramanyam R, Liao P, Sasaki E, Shapiro C, Sun Y. High STOP-Bang score indicates a high probability of obstructive sleep apnoea. British journal of anaesthesia. 2012; 108:768-775. [PubMed: 22401881]

26. Johns MW. A new method for measuring daytime sleepiness: the Epworth sleepiness scale. Sleep. 1991; 14:540-545. [PubMed: 1798888]

27. Johns MW. Reliability and factor analysis of the Epworth Sleepiness Scale. Sleep. 1992; 15:376381. [PubMed: 1519015] 
28. O'Brien LM, Bullough AS, Shelgikar AV, Chames MC, Armitage R, Chervin RD. Validation of Watch-PAT-200 against polysomnography during pregnancy. J Clin Sleep Med. 2012; 8:287-294. [PubMed: 22701386]

29. Ghegan MD, Angelos PC, Stonebraker AC, Gillespie MB. Laboratory versus portable sleep studies: a meta-analysis. Laryngoscope. 2006; 116:859-864. [PubMed: 16735890]

30. Karakis I, Chiappa KH, San Luciano M, Sassower KC, Stakes JW, Cole AJ. The Utility of Routine EEG in the Diagnosis of Sleep Disordered Breathing. Journal of Clinical Neurophysiology. 2012; 29:333-338. [PubMed: 22854767]

31. Chai-Coetzer CL, Antic NA, Rowland LS, et al. A simplified model of screening questionnaire and home monitoring for obstructive sleep apnoea in primary care. Thorax. 2011; 66:213-219. [PubMed: 21252389]

32. Berry RB, Brooks R, Gamaldo CE, Harding SM, Marcus C, Vaughn B. The AASM manual for the scoring of sleep and associated events. Rules, Terminology and Technical Specifications, Darien, Illinois. American Academy of Sleep Medicine. 2012

33. Decision Memo for Continuous Postive Airway Pressure (CPAP) Therapy for Obstructive Sleep Apnea. Centers for Medicare \& Medicaid Services. 2016

34. Adult Obstructive Sleep Apnea Task Force of the American Academy of Sleep M. Clinical Guideline for the Evaluation, Management and Long-term Care of Obstructive Sleep Apnea in Adults. Journal of Clinical Sleep Medicine: JCSM: Official Publication of the American Academy of Sleep Medicine. 2009; 5:263-276. [PubMed: 19960649]

35. Buchner NJ, Sanner BM, Borgel J, Rump LC. Continuous positive airway pressure treatment of mild to moderate obstructive sleep apnea reduces cardiovascular risk. American journal of respiratory and critical care medicine. 2007; 176:1274-1280. [PubMed: 17673692]

36. Haentjens P, Van Meerhaeghe A, Moscariello A, et al. The impact of continuous positive airway pressure on blood pressure in patients with obstructive sleep apnea syndrome: evidence from a meta-analysis of placebo-controlled randomized trials. Arch Intern Med. 2007; 167:757-764. [PubMed: 17452537]

37. Tregear S, Reston J, Schoelles K, Phillips B. Continuous positive airway pressure reduces risk of motor vehicle crash among drivers with obstructive sleep apnea: systematic review and metaanalysis. Sleep. 2010; 33:1373-1380. [PubMed: 21061860]

38. MEHRA R. Sleep apnea ABCs: Airway, breathing, circulation. Cleveland Clinic Journal of Medicine. 2014; 81:479-489. [PubMed: 25085986]

39. Yu J, Zhou Z, McEvoy R, et al. Association of positive airway pressure with cardiovascular events and death in adults with sleep apnea: A systematic review and meta-analysis. JAMA. 2017; 318:156-166. [PubMed: 28697252]

40. Ramar K, Dort LC, Katz SG, et al. Clinical Practice Guideline for the Treatment of Obstructive Sleep Apnea and Snoring with Oral Appliance Therapy: An Update for 2015. J Clin Sleep Med. 2015; 11:773-827. [PubMed: 26094920]

41. Blyton DM, Sullivan CE, Edwards N. Reduced nocturnal cardiac output associated with preeclampsia is minimized with the use of nocturnal nasal CPAP. Sleep. 2004; 27:79-84. [PubMed: 14998241]

42. Guilleminault C, Palombini L, Poyares D, Takaoka S, Huynh NT-L, El-Sayed Y. Pre-eclampsia and nasal CPAP: part 1. Early intervention with nasal CPAP in pregnant women with risk-factors for pre-eclampsia: preliminary findings. Sleep medicine. 2007; 9:9-14. [PubMed: 17644420]

43. Poyares D, Guilleminault C, Hachul H, et al. Pre-eclampsia and nasal CPAP: part 2. Hypertension during pregnancy, chronic snoring, and early nasal CPAP intervention. Sleep medicine. 2007; 9:15-21. [PubMed: 17644475]

44. Ding XX, Wu YL, Xu SJ, et al. A systematic review and quantitative assessment of sleepdisordered breathing during pregnancy and perinatal outcomes. Sleep Breath. 2014; 18:703-713. [PubMed: 24519711]

45. Spence DL, Allen RC, Lutgendorf MA, Gary VR, Richard JD, Gonzalez SC. Association of obstructive sleep apnea with adverse pregnancy-related outcomes in military hospitals. European Journal of Obstetrics and Gynecology and Reproductive Biology. 210:166-172. 
46. Pamidi S, Marc I, Simoneau G, et al. Maternal sleep-disordered breathing and the risk of delivering small for gestational age infants: a prospective cohort study. Thorax. 2016; 71:719-725. [PubMed: 27084956]

47. Ding X-X, Wu Y-L, Xu S-J, et al. A systematic review and quantitative assessment of sleepdisordered breathing during pregnancy and perinatal outcomes. Sleep and Breathing. 2014; 18:703-713. [PubMed: 24519711]

48. Ge X, Tao F, Huang K, et al. Maternal Snoring May Predict Adverse Pregnancy Outcomes: A Cohort Study in China. PLoS One. 2016; 11:e0148732. [PubMed: 26871434]

49. Tauman R, Zuk L, Uliel-Sibony S, et al. The effect of maternal sleep-disordered breathing on the infant's neurodevelopment. American Journal of Obstetrics and Gynecology. 2015; 212:656.e651656.e657. [PubMed: 25576821]

50. Salihu HM, King L, Patel P, et al. Association between maternal symptoms of sleep disordered breathing and fetal telomere length. Sleep. 2015; 38:559-566. [PubMed: 25325479]

51. Savolainen K, Eriksson JG, Kajantie E, Lahti M, Raikkonen K. The history of sleep apnea is associated with shorter leukocyte telomere length: the Helsinki Birth Cohort Study. Sleep Med. 2014; 15:209-212. [PubMed: 24360984]

52. Arnardottir ES, Mackiewicz M, Gislason T, Teff KL, Pack AI. Molecular Signatures of Obstructive Sleep Apnea in Adults: A Review and Perspective. Sleep. 2009; 32:447-470. [PubMed: 19413140]

53. Paz Y, Mar HL, Hazen SL, Tracy RP, et al. Effect of Continuous Positive Airway Pressure on Cardiovascular Biomarkers. CHEST. 150:80-90.

54. Khan N, Lambert-Messerlian G, Monteiro JF, et al. Oxidative and carbonyl stress in pregnant women with obstructive sleep apnea. Sleep and Breathing. 2017

55. Dewan NA, Nieto FJ, Somers VK. Intermittent hypoxemia and OSA: implications for comorbidities. Chest. 2015; 147:266-274. [PubMed: 25560865]

56. Chaiworapongsa T, Chaemsaithong P, Yeo L, Romero R. Pre-eclampsia part 1: current understanding of its pathophysiology. Nat Rev Nephrol. 2014; 10:466-480. [PubMed: 25003615]

57. Bourjeily G, Curran P, Butterfield K, Maredia H, Carpenter M, Lambert-Messerlian G. Placentasecreted circulating markers in pregnant women with obstructive sleep apnea. J Perinat Med. 2015; 43:81-87. [PubMed: 24846956]

58. Izci-Balserak B, Pien GW. The relationship and potential mechanistic pathways between sleep disturbances and maternal hyperglycemia. Curr Diab Rep. 2014; 14:459. [PubMed: 24398662]

59. Ryan S. Adipose tissue inflammation by intermittent hypoxia: mechanistic link between obstructive sleep apnoea and metabolic dysfunction. J Physiol. 2017; 595:2423-2430. [PubMed: 27901270]

60. Iturriaga R, Oyarce MP, Dias ACR. Role of Carotid Body in Intermittent Hypoxia-Related Hypertension. Curr Hypertens Rep. 2017; 19:38. [PubMed: 28451849]

61. Ferguson KK, Meeker JD, McElrath TF, Mukherjee B, Cantonwine DE. Repeated measures of inflammation and oxidative stress biomarkers in preeclamptic and normotensive pregnancies. Am J Obstet Gynecol. 2017; 216:527 e521-527 e529. [PubMed: 28043842]

62. Schobel HP, Fischer T, Heuszer K, Geiger H, Schmieder RE. Preeclampsia - a state of sympathetic overactivity. N Engl J Med. 1996; 335:1480-1485. [PubMed: 8890098]

63. Mohsenin V, Urbano F. Circulating antiangiogenic proteins in obstructive sleep apnea and hypertension. Respir Med. 2011; 105:801-807. [PubMed: 21277182]

64. Jafari B, Mohsenin V. Endothelial dysfunction and hypertension in obstructive sleep apnea - Is it due to intermittent hypoxia? J Cardiovasc Dis Res. 2013; 4:87-91. [PubMed: 24027362]

65. Maynard SE, Min JY, Merchan J, et al. Excess placental soluble fms-like tyrosine kinase 1 (sFlt1) may contribute to endothelial dysfunction, hypertension, and proteinuria in preeclampsia. J Clin Invest. 2003; 111:649-658. [PubMed: 12618519]

66. Levine RJ, Maynard SE, Qian C, et al. Circulating angiogenic factors and the risk of preeclampsia. N Engl J Med. 2004; 350:672-683. [PubMed: 14764923]

67. Palmer SK, Moore LG, Young D, Cregger B, Berman JC, Zamudio S. Altered blood pressure course during normal pregnancy and increased preeclampsia at high altitude (3100 meters) in Colorado. Am J Obstet Gynecol. 1999; 180:1161-1168. [PubMed: 10329872] 
68. Keyes LE, Armaza JF, Niermeyer S, Vargas E, Young DA, Moore LG. Intrauterine growth restriction, preeclampsia, and intrauterine mortality at high altitude in Bolivia. Pediatr Res. 2003; 54:20-25. [PubMed: 12700368]

69. Ilekis JV, Tsilou E, Fisher S, et al. Placental origins of adverse pregnancy outcomes: potential molecular targets: an Executive Workshop Summary of the Eunice Kennedy Shriver National Institute of Child Health and Human Development. Am J Obstet Gynecol. 2016; 215:S1-S46. [PubMed: 26972897]

70. Rosario GX, Konno T, Soares MJ. Maternal hypoxia activates endovascular trophoblast cell invasion. Dev Biol. 2008; 314:362-375. [PubMed: 18199431]

71. Genbacev O, Joslin R, Damsky CH, Polliotti BM, Fisher SJ. Hypoxia alters early gestation human cytotrophoblast differentiation/invasion in vitro and models the placental defects that occur in preeclampsia. J Clin Invest. 1996; 97:540-550. [PubMed: 8567979]

72. Lai Z, Kalkunte S, Sharma S. A critical role of interleukin-10 in modulating hypoxia-induced preeclampsia-like disease in mice. Hypertension. 2011; 57:505-514. [PubMed: 21263114]

73. Adelman DM, Gertsenstein M, Nagy A, Simon MC, Maltepe E. Placental cell fates are regulated in vivo by HIF-mediated hypoxia responses. Genes Dev. 2000; 14:3191-3203. [PubMed: 11124810]

74. Gourvas V, Dalpa E, Konstantinidou A, Vrachnis N, Spandidos DA, Sifakis S. Angiogenic factors in placentas from pregnancies complicated by fetal growth restriction (review). Mol Med Rep. 2012; 6:23-27. [PubMed: 22552373]

75. Tal R. The role of hypoxia and hypoxia-inducible factor-1alpha in preeclampsia pathogenesis. Biol Reprod. 2012; 87:134. [PubMed: 23034156]

76. Zamudio S, Wu Y, Ietta F, et al. Human placental hypoxia-inducible factor-1alpha expression correlates with clinical outcomes in chronic hypoxia in vivo. Am J Pathol. 2007; 170:2171-2179. [PubMed: 17525282]

77. Rajakumar A, Brandon HM, Daftary A, Ness R, Conrad KP. Evidence for the functional activity of hypoxia-inducible transcription factors overexpressed in preeclamptic placentae. Placenta. 2004; 25:763-769. [PubMed: 15451190]

78. Robb KP, Cotechini T, Allaire C, Sperou A, Graham CH. Inflammation-induced fetal growth restriction in rats is associated with increased placental HIF-1alpha accumulation. PLoS One. 2017; 12:e0175805. [PubMed: 28423052]

79. Nanduri J, Peng YJ, Yuan G, Kumar GK, Prabhakar NR. Hypoxia-inducible factors and hypertension: lessons from sleep apnea syndrome. J Mol Med (Berl). 2015; 93:473-480. [PubMed: 25772710]

80. Nieto FJ, Young TB, Lind BK, et al. Association of sleep-disordered breathing, sleep apnea, and hypertension in a large community-based study. Sleep Heart Health Study. JAMA. 2000; 283:1829-1836. [PubMed: 10770144]

81. Marin JM, Carrizo SJ, Vicente E, Agusti AG. Long-term cardiovascular outcomes in men with obstructive sleep apnoea-hypopnoea with or without treatment with continuous positive airway pressure: an observational study. Lancet. 2005; 365:1046-1053. [PubMed: 15781100]

82. Aronsohn RS, Whitmore H, Van Cauter E, Tasali E. Impact of untreated obstructive sleep apnea on glucose control in type 2 diabetes. Am J Respir Crit Care Med. 2010; 181:507-513. [PubMed: 20019340]

83. Bokslag A, Teunissen PW, Franssen C, et al. Effect of early-onset preeclampsia on cardiovascular risk in the fifth decade of life. Am J Obstet Gynecol. 2017; 216:523 e521-523 e527. [PubMed: 28209494]

84. Hermes W, Tamsma JT, Grootendorst DC, et al. Cardiovascular risk estimation in women with a history of hypertensive pregnancy disorders at term: a longitudinal follow-up study. BMC Pregnancy Childbirth. 2013; 13:126. [PubMed: 23734952]

85. Tobias DK, Stuart JJ, Li S, et al. Association of History of Gestational Diabetes With Long-term Cardiovascular Disease Risk in a Large Prospective Cohort of US Women. JAMA Intern Med. 2017

86. Kim C, Newton KM, Knopp RH. Gestational diabetes and the incidence of type 2 diabetes: a systematic review. Diabetes Care. 2002; 25:1862-1868. [PubMed: 12351492] 
87. Dunietz GL, Chervin RD, O'Brien LM. Sleep-disordered breathing during pregnancy: future implications for cardiovascular health. Obstet Gynecol Surv. 2014; 69:164-176. [PubMed: 25102348]

88. Ahmed R, Dunford J, Mehran R, Robson S, Kunadian V. Pre-eclampsia and future cardiovascular risk among women: a review. J Am Coll Cardiol. 2014; 63:1815-1822. [PubMed: 24613324]

89. Amaral LM, Cunningham MW Jr, Cornelius DC, LaMarca B. Preeclampsia: long-term consequences for vascular health. Vasc Health Risk Manag. 2015; 11:403-415. [PubMed: 26203257]

90. O’Sullivan JB. Diabetes mellitus after GDM. Diabetes. 1991; 40(Suppl 2):131-135. [PubMed: 1748242]

91. Louis J, Auckley D, Bolden N. Management of Obstructive Sleep Apnea in Pregnant Women. Obstetrics \& Gynecology. 2012; 119:864-868. [PubMed: 22433352]

92. Pien GW, Fife D, Pack AI, Nkwuo JE, Schwab RJ. Changes in symptoms of sleep-disordered breathing during pregnancy. Sleep. 2005; 28:1299-1305. [PubMed: 16295215]

93. Pien GW, Pack AI, Jackson N, Maislin G, Macones GA, Schwab RJ. Risk factors for sleepdisordered breathing in pregnancy. Thorax. 2014; 69:371-377. [PubMed: 24262432]

94. American Society of Anesthesiologists Task Force on Perioperative Management of patients with obstructive sleep a. Practice guidelines for the perioperative management of patients with obstructive sleep apnea: an updated report by the American Society of Anesthesiologists Task Force on Perioperative Management of patients with obstructive sleep apnea. Anesthesiology. 2014; 120:268-286. [PubMed: 24346178]

95. Lamon AM, Habib AS. Managing anesthesia for cesarean section in obese patients: current perspectives. Local Reg Anesth. 2016; 9:45-57. [PubMed: 27574464]

96. Chung F, Memtsoudis SG, Ramachandran SK, et al. Society of anesthesia and sleep medicine guidelines on preoperative screening and assessment of adult patients with obstructive sleep apnea. Anesthesia and analgesia. 2016; 123:452. [PubMed: 27442772]

97. Mhyre JM, Riesner MN, Polley LS, Naughton NN. A series of anesthesia-related maternal deaths in Michigan, 1985-2003. Anesthesiology. 2007; 106:1096-1104. [PubMed: 17525583]

98. Zaremba S, Mueller N, Heisig AM, et al. Elevated Upper Body Position Improves PregnancyRelated OSA Without Impairing Sleep Quality or Sleep Architecture Early After Delivery. Chest. 2015; 148:936-944. [PubMed: 25905714]

99. Practice Guidelines for the Prevention, Detection, and Management of Respiratory Depression Associated with Neuraxial Opioid Administration: An Updated Report by the American Society of Anesthesiologists Task Force on Neuraxial Opioids and the American Society of Regional Anesthesia and Pain Medicine. Anesthesiology. 2016; 124:535-552. [PubMed: 26655725]

100. Crowgey TR, Dominguez JE, Peterson-Layne C, Allen TK, Muir HA, Habib AS. A Retrospective Assessment of the Incidence of Respiratory Depression After Neuraxial Morphine Administration for Postcesarean Delivery Analgesia. Anesthesia \& Analgesia. 2013; 117:13681370. [PubMed: 24257387]

101. Lalmand M, Wilwerth M, Fils JF, Van der Linden P. Continuous Ropivacaine Subfascial Wound Infusion Compared With Intrathecal Morphine for Postcesarean Analgesia: A Prospective, Randomized Controlled, Double-Blind Study. Anesth Analg. 2017 


\section{KEY POINTS}

- $\quad$ All women with known or suspected sleep apnea should undergo treatment with a goal to normalize oxygenation during sleep.

- Sleep apnea is associated with hypertensive disorders of pregnancy, gestational diabetes and severe maternal morbidities including cardiomyopathy, venous thromboembolism and in hospital death.

- Management of women with sleep apnea should be multidisciplinary and include specialists in Sleep Medicine and Anesthesiology.

- $\quad$ After delivery, women with sleep apnea are at risk for severe respiratory suppression and medications which suppress respiration should be limited in use. 


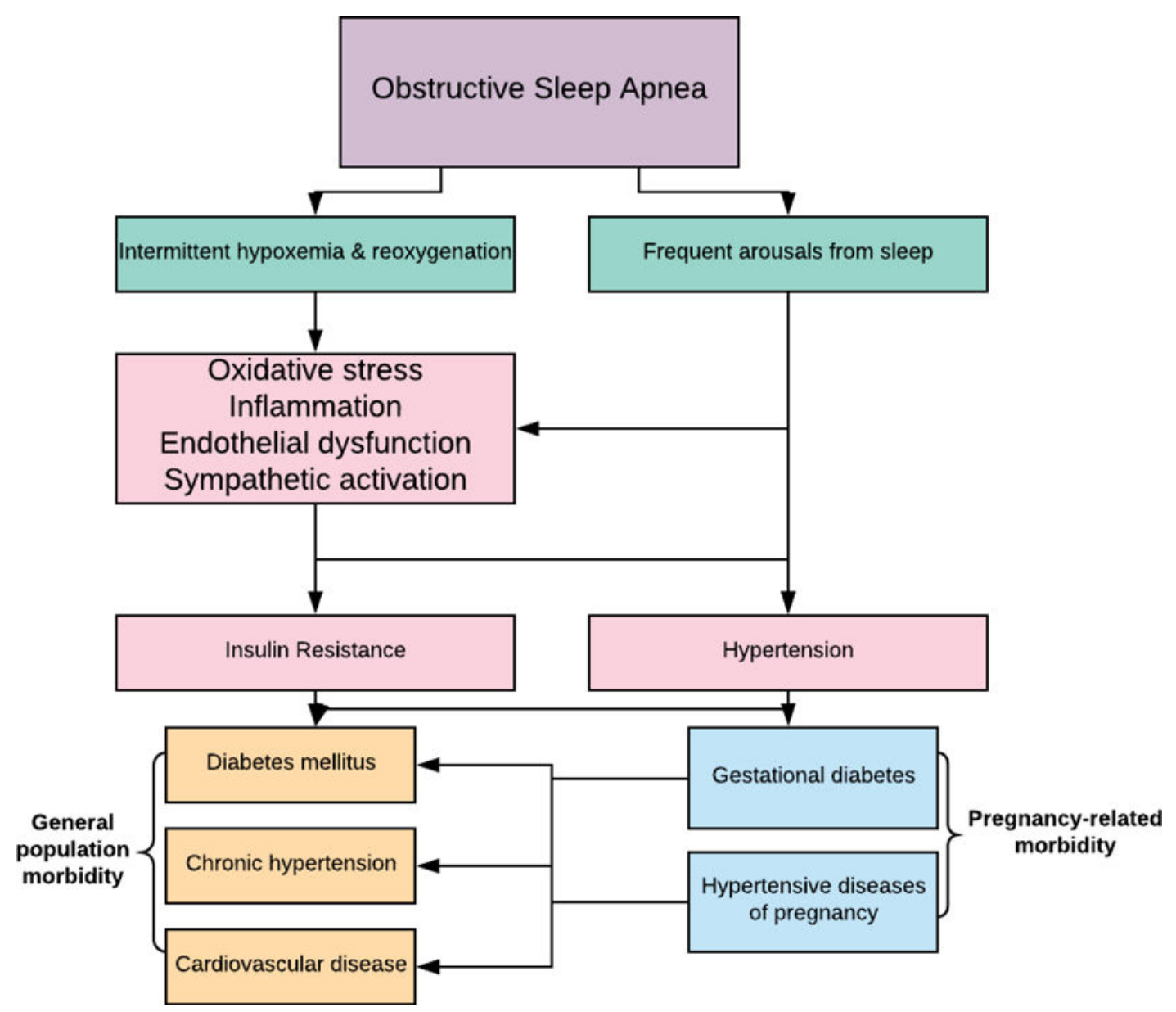

Figure 1.

The mechanisms that connect obstructive sleep apnea (OSA) in pregnant women with gestational diabetes and preeclampsia are not well-elucidated, but may share common pathways with cardiovascular and metabolic diseases associated with OSA in non-pregnant adults. OSA is associated with pro-inflammatory states, oxidative stress, and sympathetic activation. This cascade of events is thought to lead to endothelial dysfunction. Some of these same mechanisms have been implicated in the development of gestational diabetes and preeclampsia, but few studies have investigated these pathophysiologic mechanisms in women with OSA in pregnancy. 


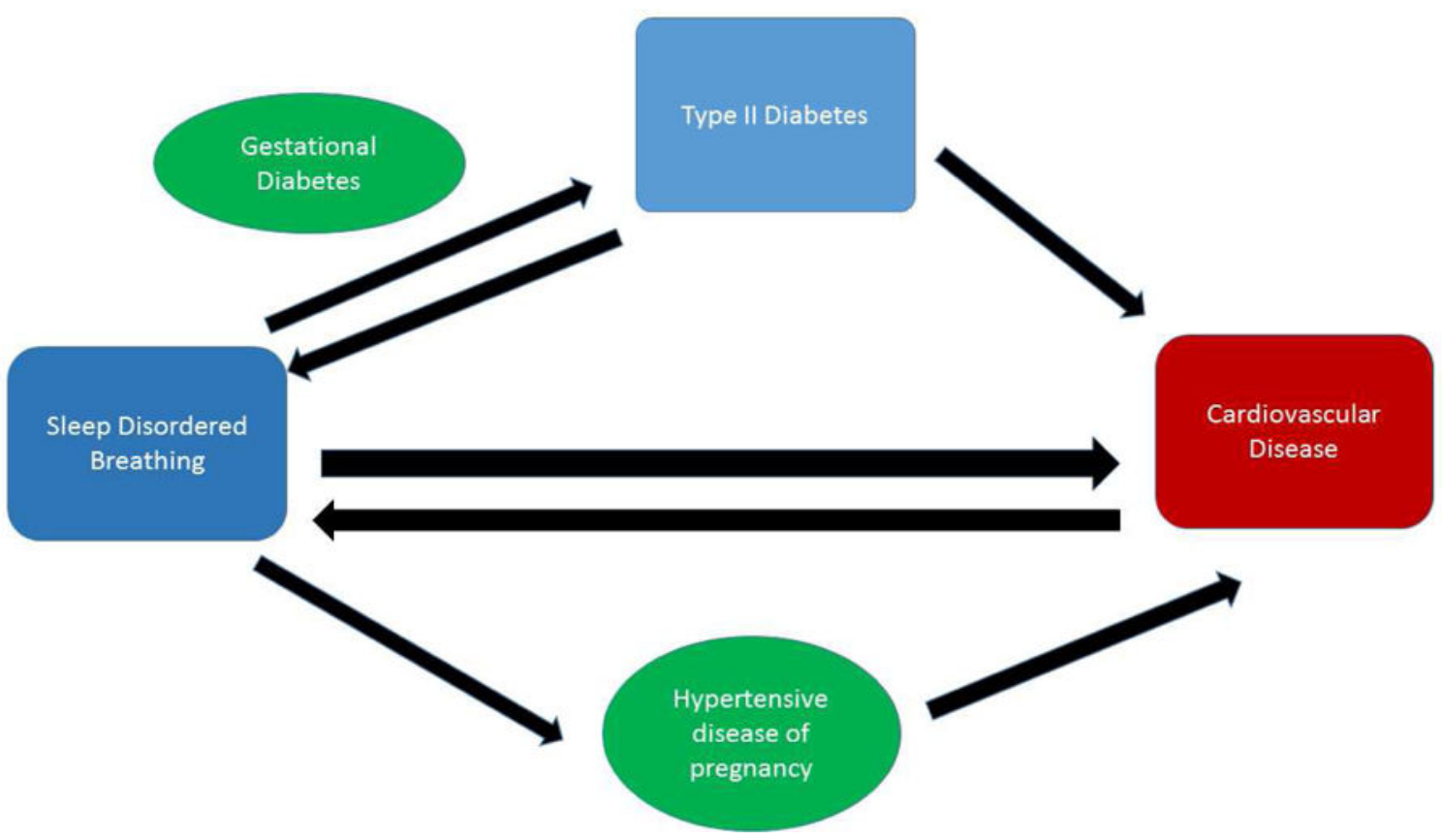

Figure 2.

Untreated sleep disordered breathing (SDB) has a bidirectional association with type II diabetes and cardiovascular disease in non-pregnant adults. SDB has also been associated with gestational diabetes and hypertensive diseases of pregnancy in recent studies.

Developing complications such as preeclampsia and gestational diabetes have been shown to increase the future risk of cardiovascular disease and type II diabetes among the affected women. 